\title{
Back Office E-Commerce Application for X Store
}

\author{
Hans Kurniawan ${ }^{1}$, Leo Willyanto Santoso ${ }^{2}$, Alexander Setiawan ${ }^{3}$ \\ ${ }^{I}$ (Informatics Business System, Petra Christian University, Indonesia) \\ ${ }^{2,3}$ (Informatics Engineering, Petra Christian University, Indonesia)
}

\begin{abstract}
X$ store is a company which their focus on sales computer accessories. In doing their business process, all sales recorded manually. Their sales using whatsapp, BBM and email for online services. The sales department had hard time to maintain their customer one by one manually. Based on this background, application designed to overcome the problems.Application was build base on website that can be accessed by sales department to maintain their sales. This will help to maintain order, when customer take an order, system will automatically check the item available or not. After that, sales department will change the status of order and customer will received and email for confirmation. Also, this application generates sales report, delivery report and stock report for manager. The website was build using PHP as the programming and MySQL databases.
\end{abstract}

Keywords: E-Commerce, Sales Report, Delivery Report, Stock Report

\section{Introduction}

$\mathrm{X}$ Store is a company that works on sales accessories computer. This company open a shop at Salatiga. Beside open a shop, they can be contacted using BBM, Whatsapp and email. After customer ordering items, sales department will checked their order and payment. After that, they will packaging and send the item. Time by time, their online sales increase rapidly, and sales department got hard time to deal with. So, X store try to use website to maintain sales. The website can help customer to got email confirmation step by step on their order. Also help manager to generate sales report, delivery report and stock report.

E-commerce is one function of internet and website can be used to business. Transaction is based on digital between company and customer.[1]

Data Flow Diagram (DFD) gives information about graphic data flow from a company. DFD divided on some level. The highest level is context diagram. This diagram explain overall company system.[3]

PHP is programming language that used to create a website. PHP is one of flexible programming language. With PHP, web developer created intregrated website with markup HTML. PHP give unlimited control on web server.[2]

MySQL is a open source database management system. MySQL can handle more than thousand table and a billion database. SQL referred to Structured Query Language based on English language and used to other database like Oracle and Microsoft SQL.[2]

\section{Materials and Methods}

\section{- Context Diagram}

Context diagram describe overall company system. In Information System E-Commerce, there is 3 entity, manager, administrator and customer. Manager is the one who received report, administrator as sales department, and customer as buyer. Context diagram can be seen at Picture 1.

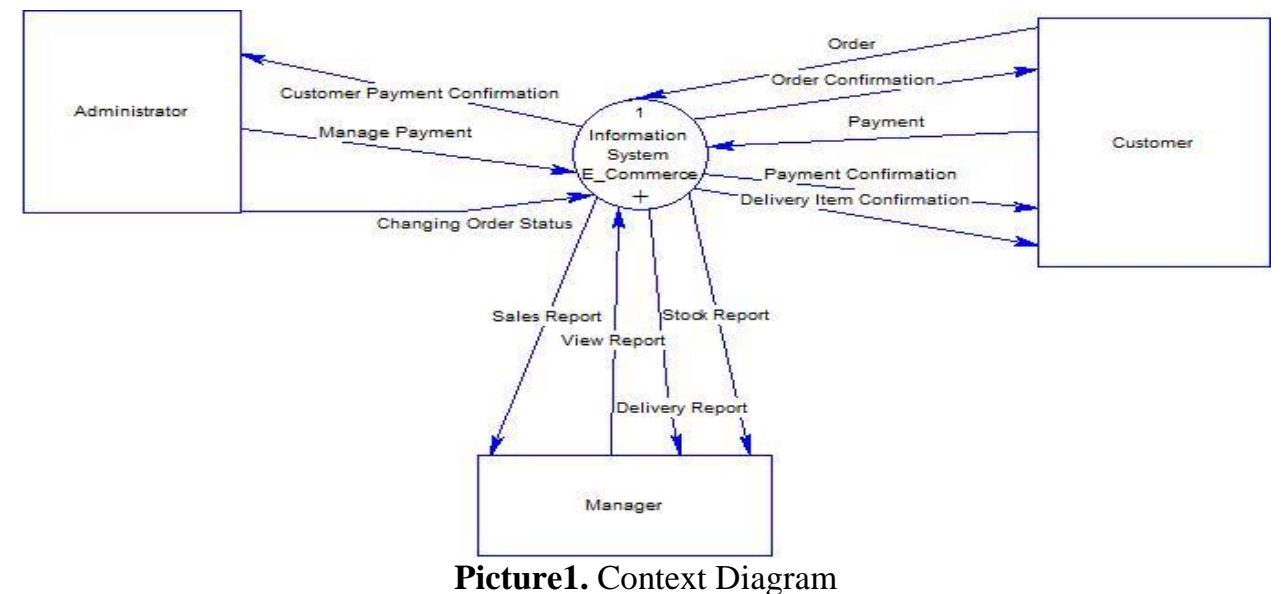




\section{- DFD Level 0}

DFD Level 0 describe detail each process in company. There is 3 process in Information System E-Commerce, sales, report, and payment. DFD Level 0 can be seen at Picture 2 .

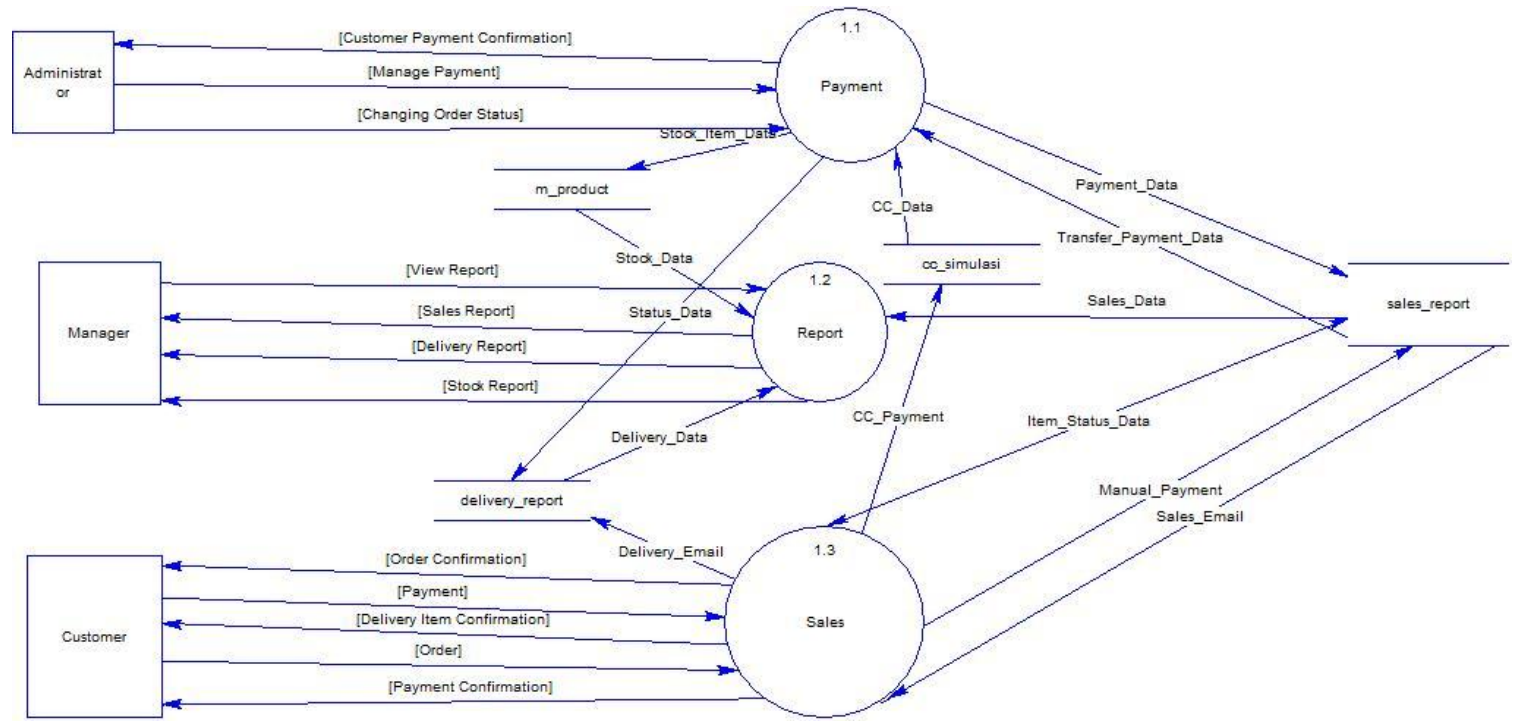

Picture2. DFD Level 0

- Login

In this website, there is login system you can choose between administrator and manager. Form login can be seen at Picture 3.

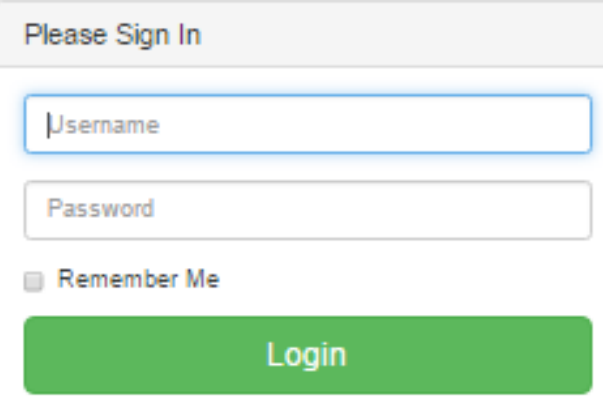

Picture 3. Form Login

\section{- Dashboard}

Dashboard administrator can be use to see how many stock less than 20. So admin can restock which item that need to. Dashboard administrator can be seen at Picture 4.
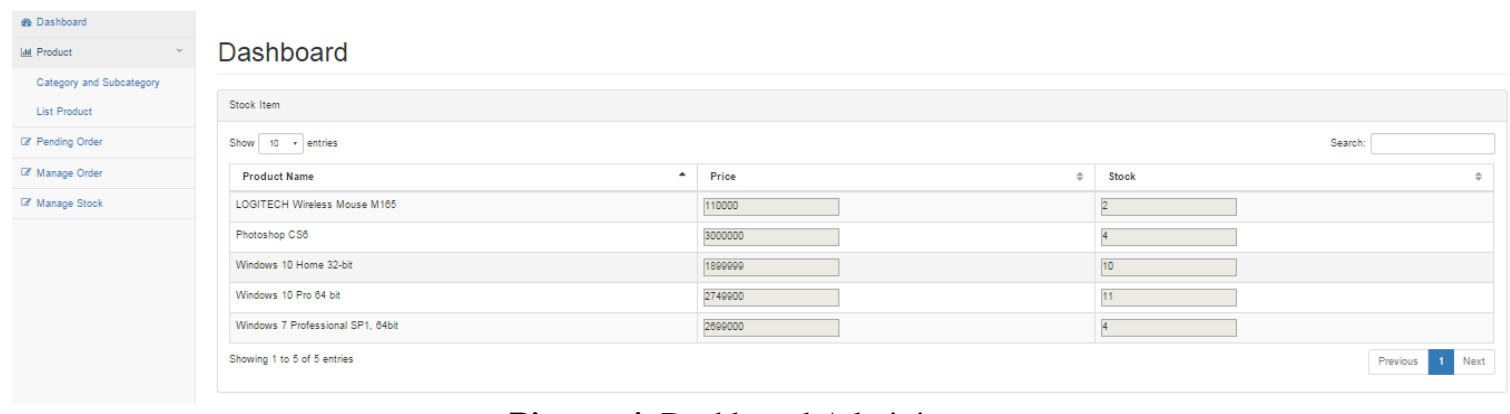

Picture 4. Dashboard Administrator

\section{- Category and Sub Category}

Manage category and subcategory is used for add type and description of product of the website. Pages management category and subcategory can be seen at Picture 5. 
Management Category \& SubCategory

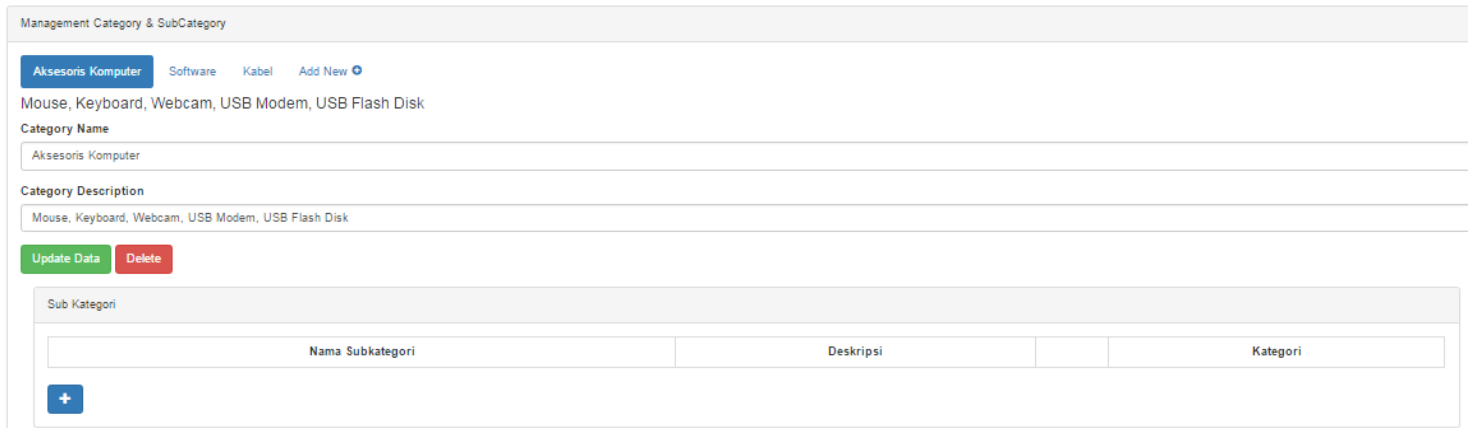

Picture 5. Management Category and Subcategory

\section{- List Product}

This page is used for add product. Administrator can input product name, product description, weight, price and stock the company have. Management product can be seen at Picture 6.

\section{Management Product}

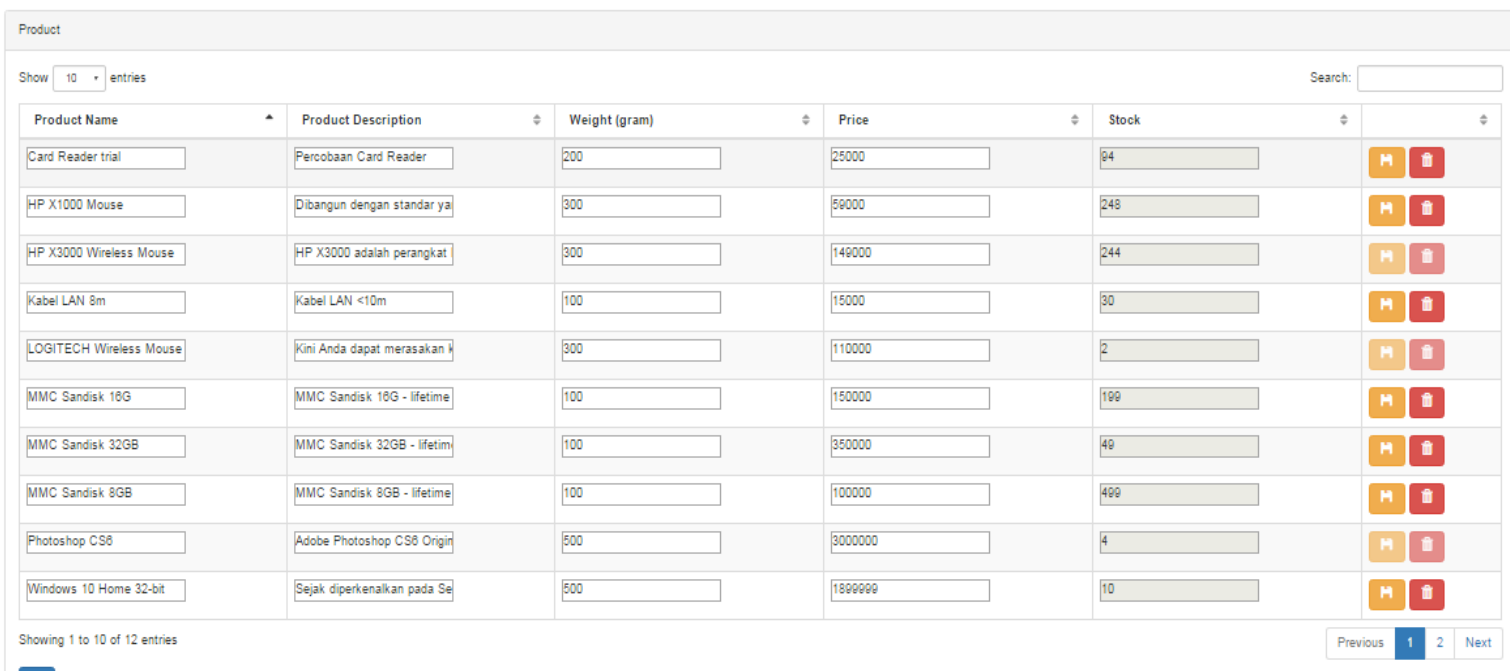

Picture 6. Management Product

\section{- Pending Order}

Pending order is used when customer buy items more than stock they have, so example when company website have 3 RAM 4GB and customer want to buy 5 RAM 4GB, so they have 2 item at pending order. Administrator have to restock first and choose pending order. Pending order page can be seen at Picture 7.

\section{Pending Orders}

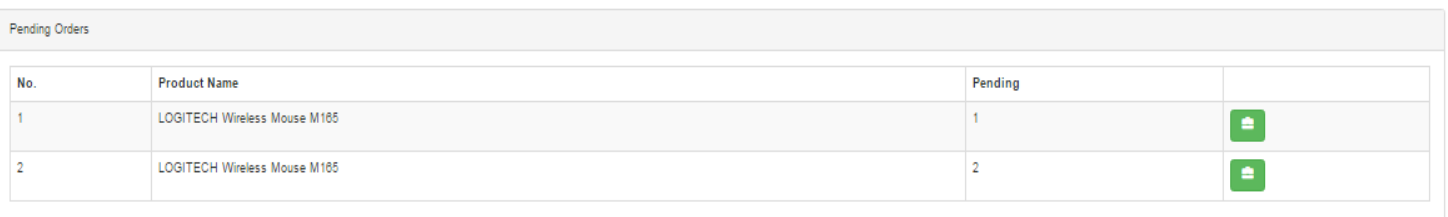

Picture 7. Pending Orders

\section{- Manage Order}

Manage order is use when there is customer's orders, administrator have to check their activities start from order, payment, packaging, delivery until transaction done. Administrator can change the status of order, after that customer will received an email from system so customer can check about their order. Manage Order can be seen at Picture 8 . 
Order Management

\begin{tabular}{|c|c|c|c|c|c|c|c|}
\hline Sales Date & yyyy-mm-dd & & s.d. & yyyy-mm-dd & & a & \\
\hline No. & Date & Product Name & & Qty & Price & Delivery & Status \\
\hline
\end{tabular}

Picture 8. Manage Order

- Manage Stock

In this page, administrator use to increase their item stock. Administrator can see product name, price and stock each item they have. When administrator want to restock, they can press button "+" beside the item stock. Manage stock can be seen at Picture 9.

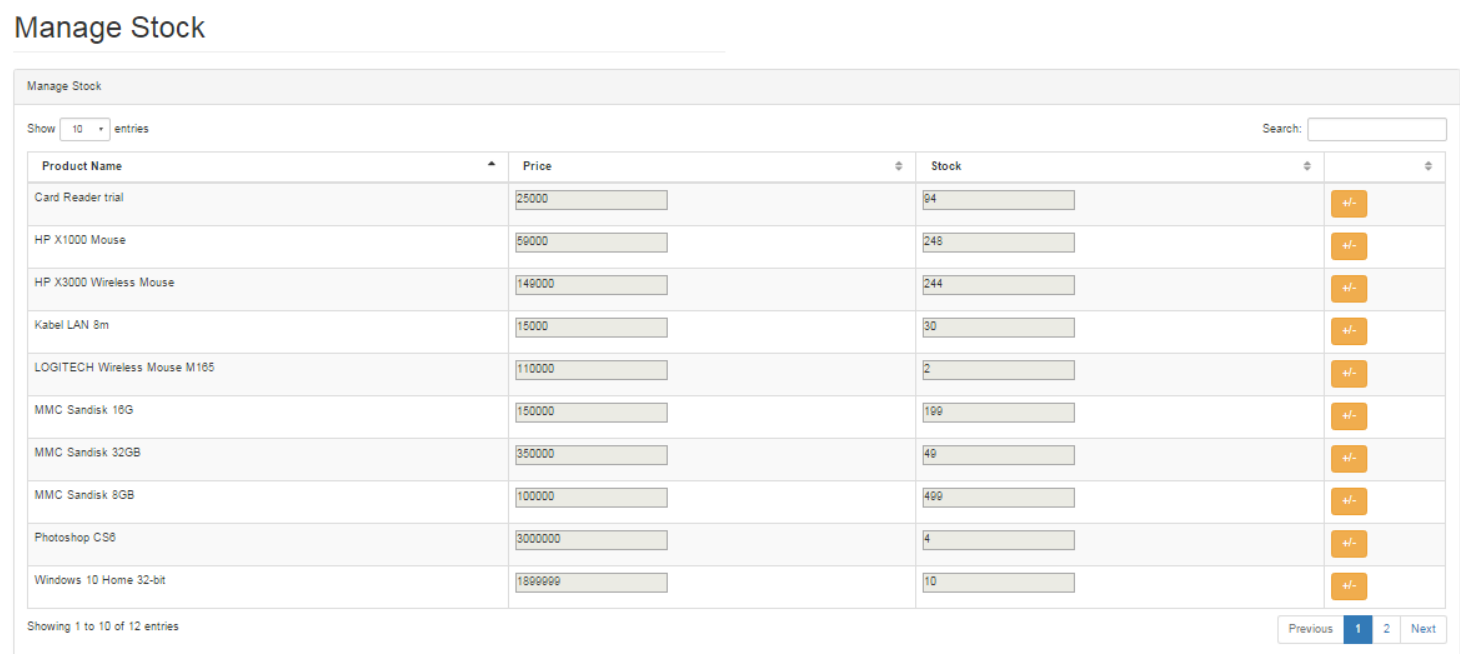

Picture 9. Manage Stock

\section{- Sales Report}

Manager can access page sales report. In this page, manager can search sales each customer and there is date search for sales report that manager wants to check. Page sales report can be seen at Picture 10. Manager also can print the report with press button "Print Report" at below.

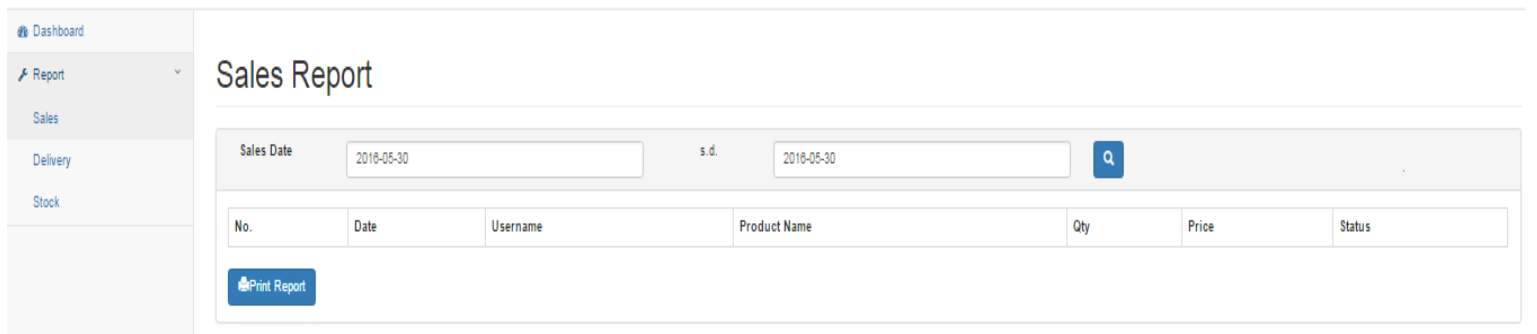

Picture 10. Sales Report

- Delivery Report

In this page, manager can check how is delivery going. Manager can monitoring sales date, delivery date, service and cost each delivery. Delivery report pages can be seen at picture 11 .

Delivery Date

\begin{tabular}{|c|c|c|c|c|c|c|}
\hline Sales Date & yyyy-mm-dd & s.d. & yyyy-mm-dd & & & \\
\hline No. & Sales Date & & & Destination & Service & Cost \\
\hline
\end{tabular}

Picture 11. Delivery Report 


\section{- $\quad$ Stock Report}

In this page, manager can check stock each item that company have. Manager also can print their stock report with press button "Print Report" below. Stock report pages can be seen at Picture 12.

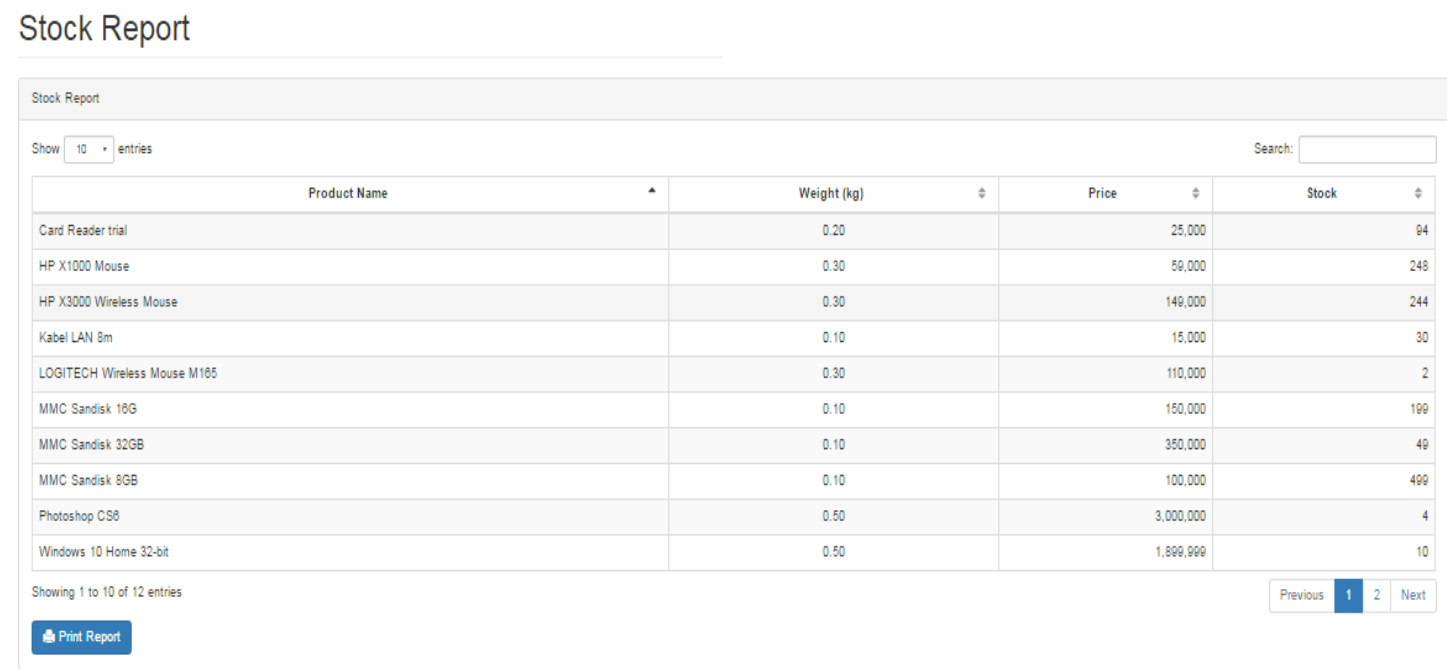

Picture 12. Stock Report.

\section{Conclusion}

- This application in accordance with company business process

- Each transaction can be monitoring by administrator,customer and manager

- Application gives sales report, delivery report and stock report accordance with reality

- This application sent email confirmation for sales when status change by administrator.

\section{References}

[1]. Laudon, C.K. \& Traver, C.G. (2011). E-Commerce 2011 business, technology, society (7th ed.) United States: Pearson.

[2]. Nixon, R. (2014). Learning PHP, MySQL, JavaScript, CSS \& HTML5 (3rd ed.). United States: O'Reilly

[3]. Romney, M.B. \& Steinbart, P.J. (2012). Accounting Information Systems (12th ed.). United States: Pearson Prentice Hall. 